\title{
JORGE LUIS BORGES E O DESARQUIVAMENTO DO SABER OCIDENTAL
}

\author{
Nabil Araújo de Souza* \\ Resumo: Partindo de uma certa aporia no próprio \\ coração do programa arqueológico foucaultiano, este \\ ensaio se volta para o modo como um texto de Borges \\ é mobilizado por Foucault no prefácio de sua opus \\ magnum, e procura mostrar que a relação heterodoxa \\ que o escritor argentino estabelece com os "arquivos" \\ da tradição ocidental antes desmobiliza do que favorece \\ a pretensão de uma arqueologia do saber. \\ Palavras-chave: Foucault; arqueologia; arquivo; Borges; \\ desarquivamento.
}

\section{O programa arqueológico foucaultiano e a questão do arquivo}

À certa altura do hoje célebre prefácio que Michel Foucault escreveu para Les mots et les choses (1966), deparamo-nos com o seguinte esclarecimento sobre o livro: "Mais que de uma história no sentido tradicional da palavra, trata-se de uma 'arqueologia"; e na nota de pé de página que então se segue: "Os problemas de método suscitados por tal 'arqueologia' serão examinados em uma próxima obra" ${ }^{1}$ Três anos mais tarde, a promessa se concretiza sob o título de L'archéologie du savoir. Por mais que o autor declare, por ocasião do novo livro, não ser este "a retomada e a descrição exata do que se pode ler em Histoire de la folie, Naissance de la clinique ou Les mots et les choses", 2 torna-se difícil, apreendendo-

\footnotetext{
* Universidade Federal de Minas Gerais.

${ }^{1}$ FOUCAULT. As palavras e as coisas, p. 12.

${ }^{2}$ FOUCAULT. A arqueologia do saber, p. 18.
} 
o como exercício de metodologia a posteriori, não se pôr a reler a mencionada trilogia à luz dos termos pelos quais o programa arqueológico então se vê (re)desenhado. E se esse programa, tal como então enunciado, tem um cerne, um núcleo-duro em vista do qual se projetaria (e se justificaria como tal) a própria démarche da arqueologia do saber, ele se encontra no conceito foucaultiano de arquivo.

Digo foucaultiano pelo fato de, na Archéologie, ${ }^{3}$ o termo arquivo ser destituído de sua acepção usual, de senso comum, para imbuir-se, idiossincraticamente, de um significado até então insuspeitado, convertendo-se, na verdade, num novo conceito - $o$ conceito central na economia interna do discurso arqueológico. Assim:

Não entendo por esse termo a soma de todos os textos que uma cultura guardou em seu poder, como documentos de seu próprio passado, ou como testemunho de sua identidade mantida; não entendo, tampouco, as instituições que, em determinada sociedade, permitem registrar e conservar os discursos de que se ter lembrança e manter a livre disposição. Tratase antes, e ao contrário, do que faz com que tantas coisas ditas por tantos homens, há tantos milênios, não tenham surgido apenas segundo o jogo das circunstâncias, que não sejam simplesmente a sinalização, no nível das performances verbais, do que se pôde desenrolar na ordem do espírito ou na ordem das coisas; mas que tenham aparecido graças a todo um jogo de relações que caracterizam particularmente o nível discursivo; que em lugar de serem figuras adventícias e como que inseridas, um pouco ao acaso, em processos mudos, nasçam segundo regularidades específicas; em suma, que se há coisas ditas - e somente estas -, não é preciso perguntar sua razão imediata às coisas que aí se encontram ditas ou

\footnotetext{
${ }^{3}$ A parte III do livro em questão intitula-se "O enunciado e o arquivo"; cf. sobretudo o capítulo $5 \mathrm{da}$ referida parte intitulado "O a priori histórico e o arquivo" (FOUCAULT. A arqueologia do saber, p. 143-149).
} 
aos homens que as disseram, mas ao sistema da discursividade, às possibilidades e às impossibilidades enunciativas que ele conduz. ${ }^{4}$

Observe-se que o gesto mesmo de delimitação do novo conceito de arquivo como "sistema da discursividade" (como "lei do que pode ser dito", como "sistema que rege o aparecimento dos enunciados como acontecimentos singulares" - mas também o "funcionamento" dos enunciados "como coisas" -, enfim: como o "sistema geral da formação e da transformação dos enunciados"), confunde-se com a rejeição ("Trata-se antes, e ao contrário...") da concepção convencional de arquivo tanto como (a) "soma de todos os textos que uma cultura guardou em seu poder, como documentos de seu próprio passado, ou como testemunho de sua identidade mantida" quanto como (b) "instituições que, em determinada sociedade, permitem registrar e conservar os discursos de que se ter lembrança e manter a livre disposição". Assim, para além do arquivo como aquilo-que-se-arquiva, como o objeto do arquivamento - a soma de textos guardados por uma cultura, a remeter a seu passado, a suas origens, à sua identidade a ser mantida -, Foucault rejeita também o arquivo como lugar não apenas como lugar-onde-se-encontra-aquilo-que-se-arquiva, a instituição onde se abriga o arquivo, mas como o próprio terlugar do arquivo, isto é, o próprio gesto do arquivamento, como movimento de reunião e conservação, no que ele pressupõe de intencionalidade e de autoridade ou legitimidade (afinal, quem permite registrar e conservar o quê? quem determina de quais discursos se ter lembrança e de quais não ter e por quê? quem mantém livre a disposição de que e para quem?).

Jacques Derrida, ${ }^{5}$ por sua vez, ao remontar, a propósito da palavra arquivo, ao vocábulo grego arkhê, lembra-nos que ele designa ao mesmo tempo o começo e o comando. "Este nome coordena aparentemente dois princípios em um", afirma o autor,

${ }^{4}$ FOUCAULT. A arqueologia do saber, p. 146-147. 
"o princípio da natureza ou da história, ali onde as coisas começam [...], mas também o princípio da lei ali onde os homens e os deuses comandam, ali onde se exerce a autoridade, a ordem social, nesse lugar a partir do qual a ordem é dada - princípio nomológico". A palavra arquivo remeteria tanto ao primeiro sentido de arkhê, "isto é, ao originário, ao primeiro, ao principal, ao primitivo, em suma, ao começo", ${ }^{6}$ quanto ao sentido nomológico do vocábulo:

Como o archivum ou o archium latino (...), o sentido de "arquivo", seu único sentido, vem para ele do arkbeîon grego: inicialmente uma casa, um domicílio, um endereço, a residência dos magistrados superiores, os arcontes, aqueles que comandavam. Aos cidadãos que detinham e assim denotavam o poder político reconhecia-se o direito de fazer ou de representar a lei. Levada em conta sua autoridade publicamente reconhecida, era em seu lar, nesse lugar que era a casa deles (...) que se depositavam então os documentos oficiais. Os arcontes foram os seus primeiros guardiões. (...) Cabiam-lhes também o direito e a competência hermenêuticos. Tinham o poder de interpretar os arquivos. Depositados sob a guarda desses arcontes, estes documentos diziam, de fato, a lei: eles evocavam a lei e convocavam à lei. Para serem assim guardados, na jurisdição desse dizer a lei, eram necessários ao mesmo tempo um guardião e uma localização. (...) No cruzamento do topológico e do nomológico, do lugar e da lei, do suporte e da autoridade, uma cena de domiciliação torna-se, ao mesmo tempo, visível e invisível. Insisto nisso por razões que (...) remetem todas a esta topo-nomologia, a esta função árquica, na verdade patriárquica, sem a qual nenhum arquivo viria à cena nem apareceria como tal. ${ }^{7}$

\footnotetext{
${ }^{5}$ DERRIDA. Mal de arquivo, p. 11.

${ }^{6}$ DERRIDA. Mal de arquivo, p. 12.

${ }^{7}$ DERRIDA. Mal de arquivo, p. 12-13.
} 
Uma tal função árquica ou arcôntica seria não apenas toponomológica, mas também consignadora: "A consignação", explica, com efeito, Derrida, "tende a coordenar um único corpus em um sistema ou uma sincronia na qual todos os elementos articulam a unidade de uma configuração ideal. (...) O princípio arcôntico do arquivo é também um princípio de consignação, isto é, de reunião".

As considerações etimológicas de Derrida em torno da noção de arquivo trazem à tona, em vista do princípio arcôntico em sua tripla função: topológica-nomológica-consignadora, a dimensão de intencionalidade e de autoridade (política, jurídica, hermenêutica, epistemológica) inerente ao ter-lugar do arquivo, à sua realização institucional, ao arquivamento como instituição, institucionalização do arquivo. "Uma ciência do arquivo deve incluir a teoria desta institucionalização, isto é, ao mesmo tempo, da lei que aí se inscreve e do direito que a autoriza", sentencia, a propósito, Derrida. ${ }^{9}$

Ora, não é justamente a essa tarefa que se furta o projeto arqueológico foucaultiano ao desvencilhar-se da concepção usual de arquivo e daquilo que ela implicaria em termos arcônticos ou (patri)árquicos? Por outro lado, não é justamente essa problemática topológica-nomológica-consignadora que haveria de necessariamente emergir, ao modo de um retorno do recalcado, quando, mais cedo ou mais tarde, o pensamento arqueológico se visse enredado na incontornável aporia implicada pela questão da "arqueologia da arqueologia"?

\footnotetext{
${ }^{8}$ DERRIDA. Mal de arquivo, p. 14.

${ }^{9}$ DERRIDA. Mal de arquivo, p. 14.
} 


\section{A incontornável aporia: necessidade/impossibilidade de uma arqueologia da arqueologia}

$\mathrm{O}$ arquivo, tal como concebido por Foucault, funcionaria ao modo de um "a priori histórico" - termo cunhado pelo autor em contraste com o "a priori formal" da tradição da filosofia idealista pós-kantiana. Em ambos os casos, trata-se de definir uma instância a funcionar como condição de possibilidade do conhecimento (dos "discursos de conhecimento", no caso de Foucault) que se impusesse, de modo não-consciente, como necessária para todos os indivíduos a ela submetidos.

Diferentemente, entretanto, do a priori formal idealista, que se quer necessário universal e atemporalmente, o a priori foucaultiano seria histórico por não escapar, ele próprio, à historicidade, configurando-se, pois, como um "conjunto transformável". ${ }^{10} \mathrm{O}$ que não quereria dizer, contudo, que, no âmbito estrito de sua vigência histórica limitada, ele não se impusesse como necessário. Apesar de limitada historicamente, essa pretensa necessidade comandaria mesmo as práticas discursivas (de toda uma cultura, de toda uma época) sem que os protagonistas dessas práticas - múltiplas, diversas, convergentes, divergentes disso se dessem conta, ao modo de "uma trama que não dominam, cujo todo não percebem e cuja amplitude medem mal". ${ }^{11}$

Além de não-subjetivo ou não-intencional, o sistema de discursividade a funcionar como a priori histórico seria também não-epistêmico, isto é, não diria respeito à veracidade ou à validade dos discursos, mas apenas à sua existência ou possibilidade. Em outras palavras, ele determinaria a existência dos discursos pura e simplesmente como discursos e não como discursos válidos ou verdadeiros. "Quero designar um a priori

\footnotetext{
${ }^{10}$ FOUCAULT. A arqueologia do saber, p. 145.

${ }^{11}$ FOUCAULT. A arqueologia do saber, p. 144.
} 
que não seria condição de validade para juízos, mas condição de realidade para enunciados", disse, com efeito, Foucault; e ainda: "Não se trata de reencontrar o que poderia tornar legítima uma assertiva, mas isolar as condições de emergência dos enunciados, a lei de sua coexistência com outros, a forma específica de seu modo de ser, os princípios segundo os quais subsistem, se transformam e desaparecem". ${ }^{12}$

Foucault chama de arquivo, como vimos, ao "sistema geral da formação e da transformação dos enunciados”. À arqueologia caberia justamente descrever "os discursos como práticas especificadas no elemento do arquivo". ${ }^{13}$ Pareceria natural, então, reler o trabalho historiográfico previamente levado a cabo por Foucault como a realização exemplar de um tal programa de investigação, com foco em campos diversos do saber europeu moderno: os discursos sobre a loucura, o desenvolvimento do olhar médico, o surgimento das ciências humanas - o que haveria de garantir, além do mais, coesão e coerência internas ao empreendimento arqueológico foucaultiano como um todo. Essa coesão e essa coerência é que se veem ameaçadas, contudo, quando da emergência, no seio da própria reflexão arqueológica - como desenvolvimento natural e consequente de sua própria problemática, poder-se-ia dizer - de uma indagação tão incômoda quanto incontornável para o tipo de investigação imaginado por Foucault: a indagação pelo que se poderia chamar uma "arqueologia da arqueologia".

"É evidente que não se pode descrever exaustivamente o arquivo de uma sociedade, de uma cultura ou de uma civilização; nem mesmo, sem dúvida, o arquivo de toda uma época", afirma Foucault,${ }^{14}$ reconhecendo uma limitação natural ao alcance da

\footnotetext{
12 FOUCAULT. A arqueologia do saber, p. 144.

${ }^{13}$ FOUCAULT. A arqueologia do saber, p. 149.

${ }^{14}$ FOUCAULT. A arqueologia do saber, p. 148.
} 
investigação arqueológica tal como por ele concebida, limitação que não ameaçaria, contudo, o edifício da arqueologia do saber, seja como programa, seja como realização (afinal de contas, nenhuma descrição, do que quer que seja, por quem quer que seja, pode pretender-se efetivamente exaustiva ou completa). $\mathrm{O}$ que Foucault admite, logo na sequência, entretanto, é algo cujas consequências para o pensamento arqueológico seriam bem mais graves do que o mero reconhecimento de uma limitação de alcance. "Por outro lado, não nos é possível descrever nosso próprio arquivo", explica, com efeito, Foucault, "já que é no interior de suas regras que falamos, já que é ele que dá ao que podemos dizer - e a ele próprio, objeto de nosso discurso - seus modos de aparecimento, suas formas de existência e de coexistência, seu sistema de acúmulo, de historicidade e de desaparecimento". ${ }^{15}$

Foucault nos fala, pois, de uma impossibilidade: a arqueologia, a "ciência" do arquivo, cuja tarefa seria justamente a de descrever a dimensão do arquivo que se diz presidir às práticas discursivas de uma dada sociedade, de uma dada cultura, de uma dada época, encontra-se, não obstante, definitivamente impossibilitada de descrever o arquivo a partir do qual ela própria operaria, as regras, o sistema de discursividade que tornaria possível o próprio discurso arqueológico como discurso. Isso, num determinado sentido, já era previsível, uma vez que, como vimos, o arquivo, segundo a própria teoria arqueológica, caracterizar-se-ia por não-subjetivo ou não-intencional, permanecendo, portanto, não-consciente para os indivíduos a ele submetidos; o que não melhora as coisas, evidentemente, posto que permanece a escandalosa contradição de uma "ciência" do arquivo - e que, como tal, deveria ser capaz de descrever qualquer arquivo - à qual se encontra irreversivelmente inacessível o conhecimento de seu próprio arquivo.

As coisas, na verdade, pioram, quando se leva em conta a incontornável necessidade de uma tal tarefa, a despeito de sua

${ }^{15}$ FOUCAULT. A arqueologia do saber, p. 148. 
impossibilidade. Foucault reconhece, como vimos, a impossibilidade de o discurso arqueológico descrever o arquivo que o possibilita como discurso, ainda que a tarefa da arqueologia se defina como a descrição do arquivo. "Entretanto", ele se pergunta na sequência, "como poderia essa descrição do arquivo justificar-se, elucidar o que a torna possível, demarcar o lugar de onde ela própria fala, controlar seus deveres e seus direitos, testar e elaborar seus conceitos (...), se se obstinava em descrever somente os horizontes mais longínquos?" E ainda: "Não será preciso nos reaproximarmos o máximo possível dessa positividade a que ela própria obedece, e do sistema de arquivo que nos permite falar, hoje, do arquivo em geral?". ${ }^{16}$ Observe-se que não é outro senão o problema da justificação do discurso arqueológico ("como poderia essa descrição do arquivo justificar-se...?”), isto é, de sua legitimidade como discurso de conhecimento, que aí emerge e se impõe. É justamente a problemática nomológica do arquivo/arquivamento, em sua feição jurídico-epistemológica ("como poderia essa descrição do arquivo... controlar seus deveres e seus direitos...?”), previamente recalcada na deposição foucaultiana da concepção convencional de arquivo, que então retorna, instaurando a aporia de uma necessidade ao mesmo tempo incontornável e de antemão impossível de ser satisfeita: a arqueologia nunca terá acesso a seu próprio arquivo, mas, sem tomar ciência das regras que presidem seu discurso, como justificar-se, legitimar-se como prática discursiva, como discurso de conhecimento "sobre o discurso"?

A problemática do arquivo encontra-se na base do programa arqueológico delineado em L'archéologie du savoir. Afinal, qual é o sistema de arquivo que permitiria falar do arquivo em geral? - pergunta-se, a propósito, Foucault. A arqueologia é incapaz de responder a essa pergunta. A prática arqueológica tal como ilustrada, se quisermos, por Histoire de la folie, Naissance de la clinique, Les mots et les choses - pressupõe, na verdade, o

${ }^{16}$ FOUCAULT. A arqueologia do saber, p. 148. 
arquivamento do conceito de arquivo, bem como do próprio conceito de arqueologia (a conceituação identificando-se, bem entendido, com o gesto mesmo do arquivamento), arquivamento esse que permaneceria, contudo, como o impensado dessa mesma prática.

Nesses termos, haveria, em Foucault, de um lado, ou num primeiro momento, a emergência de uma certa problemática do arquivo e seu subsequente arquivamento nos conceitos de arquivo e de arqueologia, e, de outro lado, ou num segundo momento, uma prática historiográfica e/ou arqueológica pretensamente fundamentada por um tal arquivamento. Daí, a pergunta: não seria possível eliminar o hiato entre essas duas instâncias discursivas, isto é, a de um pensamento arqueológico que procede ao arquivamento de um universo conceitual e de um programa de investigação, por um lado, e de uma práxis arqueológica que pressupõe, como tal, o referido arquivamento, mas que permanecerá cega para o mesmo, ainda que possibilitada por ele? Ou ainda: não seria possível reler o trabalho historiográfico foucaultiano, sua trilogia arqueológica, em sua contingência enunciativa, isto é, como se, ao invés de fundamentado por uma teoria do arquivo já estabelecida previamente, se afigurasse, antes, performaticamente, como o próprio gesto de enunciação da problemática do arquivo, da problemática arqueológica, ao modo de uma grande questão, de um longo pôr-em-questão, cujo desenrolar, equivaleria, além do mais, ao diferimento, ao adiamento de seu próprio arquivamento?

\section{Borges e o desarquivamento do saber ocidental}

Logo na abertura do já referido prefácio a Les mots et les choses, lê-se que "Este livro nasceu de um texto de Borges". ${ }^{17} \mathrm{O}$

${ }^{17}$ FOUCAULT. As palavras e as coisas, p. 5. 
texto em questão - cujo título e o livro de que faz parte não são mencionados por Foucault, nem no original nem na tradução francesa - chama-se "El idioma analítico de John Wilkins" e encontra-se em Otras inquisiciones (1952).

Podemos encarar, é certo, desde o início, a referência ao texto de Borges (e a apropriação que dele faz Foucault nas páginas subsequentes) em vista da função meramente retórica que ela realmente pareceria desempenhar na economia interna do prefácio. Ou algum leitor creditará, de fato, à leitura do texto borgiano o nascimento de Les mots et les choses - como se, em desconhecendo o escritor argentino, o pensador francês nunca tivesse escrito sua obra-prima? A presença da palavra arqueologia no subtítulo do livro deveria, ao contrário, prevenir-nos contra uma tal ingenuidade, chamando nossa atenção para o caráter devidamente arquitetado, por assim dizer, da narrativa com que então havemos de nos deparar. Nada nos impediria, por outro lado, de tomar a frase de abertura a sério, mais a sério do que o próprio Foucault sequer teria imaginado, o que poderia nos levar, contudo, a reconceber a aventura arqueológica ali encenada como tendo sido escrita pelo próprio Borges.

No prefácio a seu livro, Foucault se detém no desde então muito citado e comentado trecho do texto de Borges que faz menção a uma certa enciclopédia chinesa segundo a qual os animais se dividem em: "(a) pertencentes ao Imperador, (b) embalsamados, (c) amestrados, (d) leitões, (e) sereias, (f) fabulosos, (g) cães soltos, (h) incluídos nesta classificação, (i) inumeráveis, (k) desenhados com um finíssimo pêlo de camelo, (l) etcétera, (m) que acabam de quebrar o vaso, (n) que de longe parecem moscas". ${ }^{18}$ Citado o trecho em questão, Foucault imediatamente constata: "No deslumbramento dessa taxinomia, o que de súbito atingimos, o que, graças ao apólogo, nos é indicado como o encanto exótico de um outro pensamento, é o limite do nosso: a impossibilidade

${ }^{18}$ BORGES. O idioma analítico de John Wilkins, p. 94. 
patente de pensar isso". Mas, impossibilidade de se pensar o quê? "Que coisa, pois, é impossível pensar, e de que impossibilidade se trata?", pergunta-se Foucault. ${ }^{19}$

Talvez o caráter fantástico ou fabuloso de determinadas categorias de seres ali arroladas - poder-se-ia responder. Não pondera Foucault -, uma vez que tais animais são explicitamente designados como fabulosos. O que nos seria impossível pensar é "a estreita distância segundo a qual [tais animais fabulosos] são justapostos aos cães em liberdade ou àqueles que de longe parecem moscas". Em suma: "O que transgride toda imaginação, todo pensamento possível, é simplesmente a série alfabética (a, b, c, d) que liga a todas as outras cada uma dessas categorias." 20

Mas a quem, afinal, esse modo de ordenamento pareceria impossível? Ao autor, por certo, e, presumivelmente, a seus leitores. Foucault observa, a propósito, que a essa "distorção da classificação", a esse "quadro sem espaço coerente" impossíveis de serem por nós pensados, Borges "dá como pátria mítica uma região precisa, cujo simples nome constitui para o Ocidente uma grande reserva de utopias": a China. Daí a constatação: "haveria, assim, na outra extremidade da terra que habitamos, uma cultura votada inteiramente à ordenação da extensão, mas que não distribuiria a proliferação dos seres em nenhum dos espaços onde nos é possível nomear, falar, pensar". ${ }^{21}$

Ora, perguntamo-nos, o que aí assistimos não seria mais uma cena do clássico drama antropológico no qual o Ocidente, em contato ou choque com seu Outro oriental, se vê de alguma forma levado, em função do reconhecimento de certas diferenças cognitivas aparentemente incontornáveis, a perceber a arbitrariedade inerente a seu próprio padrão cognitivo - o que levaria, por extensão, a uma compreensão mais relativista das culturas e visões

\footnotetext{
${ }^{19}$ FOUCAULT. As palavras e as coisas, p. 5.

${ }^{20}$ FOUCAULT. As palavras e as coisas, p. 6.

${ }^{21}$ FOUCAULT. As palavras e as coisas, p. 9.
} 
de mundo? "Quando instauramos uma classificação refletida, quando dizemos que o gato e o cão se parecem menos que dois galgos, mesmo se ambos estão adestrados ou embalsamados, mesmo se os dois correm como loucos e mesmo se acabam de quebrar a bilha, qual é, pois, o solo a partir do qual podemos estabelecê-lo com inteira certeza?", indagar-se-á, com efeito, Foucault; e ainda: "Em que 'tábua', segundo qual espaço de identidades, de similitudes, de analogias, adquirimos o hábito de distribuir tantas coisas diferentes e parecidas?"; e ainda: "Que coerência é essa que se vê logo não ser nem determinada por um encadeamento a priori e necessário, nem imposta por conteúdos imediatamente sensíveis?"22

A pergunta pelo "solo", "tábua" ou "espaço" de identidades/ similitudes/analogias que se diria presidir nossas classificações e ordenamentos do mundo, o modo como distribuímos as coisas em vista de certas diferenças e semelhanças (e não de outras), será mais tarde respondida, em L'archéologie du savoir, por meio da sistematização dos conceitos de $a$ priori histórico e de arquivo. No prefácio ao livro de 1966, aquém, ainda, dessa sistematização por vir, a problemática arqueológica já se encontra, contudo, claramente enunciada, nos seguintes termos: (a) "Assim, em toda cultura, entre o uso do que se poderia chamar os códigos ordenadores e as reflexões sobre a ordem, há a experiência nua da ordem e de seus modos de ser"; (b) "No presente estudo, é essa experiência que se pretende analisar. Trata-se de mostrar o que ela veio a se tornar, desde o século XVI, no meio de uma cultura como a nossa"; (c) "[é] um estudo que se esforça por encontrar a partir de que foram possíveis conhecimentos e teorias; segundo qual espaço de ordem se constituiu o saber; na base de qual a priori histórico e no elemento de qual positividade puderam aparecer ideias, constituir-se ciências, refletir-se experiências em filosofias". ${ }^{23}$ Conhece-se bem a narrativa

\footnotetext{
${ }^{22}$ FOUCAULT. As palavras e as coisas, p. 9.
}

${ }^{23}$ FOUCAULT. As palavras e as coisas, p. 11. 
que daí emergirá; tal como Foucault a resume: "esta investigação arqueológica mostrou duas grandes descontinuidades na episteme da cultura ocidental: aquela que inaugura a idade clássica (por volta dos meados do século XVI) e aquela que, no início do século XIX, marca o limiar de nossa modernidade". ${ }^{24}$

Mas em que medida Foucault estaria, aí, a descrever sua própria episteme? Foucault de fato intui, como vimos, a propósito do texto de Borges, uma episteme, uma ordem do saber que seria a sua (a "nossa"?, a do "Ocidente"?), em contraposição a uma outra ordem, "chinesa", "oriental". Les mots et les choses dedica-se à explicitação dessa "episteme ocidental", mas apenas à medida que ela já não é mais a "nossa”, a de Foucault, já não é mais, em suma, a episteme, o a priori da arqueologia foucaultiana, o qual permanecerá insondável à pesquisa arqueológica ela mesma. É a aporia da "arqueologia da arqueologia", como já se terá percebido, que então emerge em sua incontornabilidade: "Tentando trazer à luz esse profundo desnível da cultura ocidental, é a nosso solo silencioso e ingenuamente imóvel que restituímos suas rupturas, sua instabilidade, suas falhas; e é ele que se inquieta novamente sob nossos passos". ${ }^{25}$ Retornando, contudo, à cena antropológica projetada a partir da leitura de Borges e, daí, ao próprio texto de Borges lido por Foucault, uma outra narrativa parece deixar-se entrever a propósito de Les mots et les choses - e, por que não, de Histoire de la folie, de Naissance de la clinique.

Foucault apreende a citação borgiana da enciclopédia chinesa como se a mesma figurasse uma classificação necessariamente "distorcida", um quadro necessariamente "incoerente" aos olhos do que ele chama de "nosso pensamento" - o dele próprio, por certo, mas também, presume-se, o de seus leitores, além, é claro, o de Borges. Isso tudo revela a convicção de uma homogeneidade do "pensamento ocidental" - pretensamente compartilhado por

\footnotetext{
${ }^{24}$ FOUCAULT. As palavras e as coisas, p. 12.

${ }^{25}$ FOUCAULT. As palavras e as coisas, p. 14.
} 
Borges e seus leitores, entre os quais o próprio Foucault, mas também os leitores de Foucault, que saberiam bem do que ele está falando quando se refere ao "riso que, com sua leitura [a leitura de Borges], perturba todas as familiaridades do pensamento - do nosso: daquele que tem nossa idade e nossa geografia" ${ }^{26}$ - em contraposição ao "pensamento oriental" ilustrado pela enciclopédia chinesa. A leitura do próprio texto de Borges, contudo, não nos parece contribuir para uma tal visão das coisas.

Antes de mais nada, seria preciso notar que quem privilegia o exemplo "oriental", ou "não-ocidental", a propósito do caráter "insólito" inerente à atividade de classificação e ordenação do mundo e das coisas é Foucault e não Borges. O foco principal do texto de Borges, ao contrário, é, antes, John Wilkins, referido no próprio título (que Foucault opta por não mencionar), um pensador inglês (ocidental, portanto), do século XVII, que propôs, por volta de 1664, "a formação de um idioma analítico, geral, que organizasse e abrangesse todos os pensamentos humanos". ${ }^{27} \mathrm{Na}$ base do tal idioma se encontraria uma "tabela quadragesimal" elaborada por Wilkins, de acordo com a qual, por exemplo, as pedras dividir-se-iam em "comuns (pederneira, cascalho, piçarra), módicas (mármore, âmbar, coral), preciosas (pérola, opala), transparentes (ametista, safira) e insolúveis (hulha, greda e arsênico)" ${ }^{28}$ Borges menciona ainda o Instituto Bibliográfico de Bruxelas - que "parcelou o universo em 1000 subdivisões, correspondendo a 262 ao Papa; a 282 à Igreja Católica Romana; a 263 ao Dia do Senhor; a 268 às escolas dominicais; a 298 ao mormonismo; e a 294 ao bramanismo, budismo, xintoísmo e taoísmo”; e ainda: "a 179: 'Crueldade com os animais. Proteção dos animais. O duelo e o suicídio do ponto de vista da moral. Vícios e defeitos vários. Virtudes e qualidades várias"'. ${ }^{29}$ Borges refere-

\footnotetext{
${ }^{26}$ FOUCAULT. As palavras e as coisas, p. 5.

${ }^{27}$ BORGES. O idioma analítico de John Wilkins, p. 93.

${ }^{28}$ BORGES. O idioma analítico de John Wilkins, p. 94.

${ }^{29}$ BORGES. O idioma analítico de John Wilkins, p. 94.
} 
se também à tal enciclopédia chinesa, mencionada, na verdade, por um certo doutor Franz Kuhn, por sua vez mencionado por Borges.

Tais sistemas classificatórios são considerados por Borges arbitrários: "Registrei as arbitrariedades de Wilkins, do desconhecido (ou apócrifo) enciclopedista chinês e do Instituto Bibliográfico de Bruxelas", diz-nos, com efeito. Mas não há nada aí como a declaração de estranhamento de Foucault falando a partir do que acredita ser seu próprio sistema de pensamento, então evidenciado pelo contraste com o Outro. Na verdade, diz-nos Borges, "não há classificação do universo que não seja arbitrária e conjetural" ${ }^{30}$

Essa constatação é possibilitada não por um ponto de vista privilegiado, ao modo de uma pretensa meta-teoria arqueológica que permitisse desvendar o arquivo subjacente aos sistemas discursivos em questão, e sim, ao invés, pela inexistência mesma de um tal ponto de vista, por uma sensação de desconbecimento que o impediria de atribuir a qualquer esquema cognitivo em particular o privilégio epistêmico que faria dele preferível aos demais. A razão, portanto, para não haver classificações do universo que não sejam arbitrárias seria "muito simples", segundo Borges: "não sabemos o que é o universo". ${ }^{31} \mathrm{Na}$ contramão do programa arqueológico como um saber sobre os saberes (ou sobre os discursos do saber), a visada borgiana caracterizada por um não-saber teria como efeito a reversão dos saberes instituídos, o desarquivamento dos saberes arquivados, em direção a um espaço ou um estado de indecidibilidade epistemológica.

Um tal efeito reversivo ou desarquivador não seria bem compreendido tomando-se Borges pura e simplesmente como um escritor "ocidental", como quer Foucault. Tampouco, inversamente, pela referência a algo como uma "essência" hispano-americana ou latino-americana.

\footnotetext{
${ }^{30}$ BORGES. O idioma analítico de John Wilkins, p. 94.

${ }^{31}$ BORGES. O idioma analítico de John Wilkins, p. 94.
} 
Borges não acreditava, com efeito, no especificamente hispano-americano, no especificamente latino-americano, sequer no especificamente americano. Certa vez, declarou: "Ser americano é um modo mais amplo de ser europeu, já que não somos outra coisa" ${ }^{32}$ Trata-se de uma afirmação em plena consonância com a concepção ocidentalista da América como extensão ou ampliação da Europa ${ }^{33}$ uma daquelas declarações típicas que, frequentemente citadas em isolamento, contribuíram diretamente para a imagem de Borges como um conservador em termos culturais e políticos. As afirmações seguintes parecem, a princípio, ir no mesmo sentido, mas introduzem alguns ruídos no topos "América-como-extensãoda-Europa”, os quais não deveriam passar despercebidos:

(1) Todos somos europeus desterrados, nossa cultura é a cultura ocidental, e não a indígena, certamente; ${ }^{34}$

(2) A América é uma Europa no exílio. A cultura da América do Norte, assim como a da América Latina, são amplificações e, em parte, deformações do Ocidente europeu. Digo deformações porque estas culturas, atravessando o oceano, se acharam em um espaço mais amplo e um tempo mais curto em relação ao da tradição européia. ${ }^{35}$

Observe-se que o "modo mais amplo de ser europeu" que definia o "ser americano" na primeira passagem citada, recebe,

\footnotetext{
32 BORGES. América Latina, p. 18.

33 "O ocidentalismo, e não o colonialismo", explica-nos, a propósito, MIGNOLO (Histórias locais/projetos globais, p. 138), "foi a principal preocupação, primeiro, da coroa espanhola e dos letrados durantes os séculos 16 e 17, e, segundo, do Estado e dos intelectuais durante o período da construção das nações, que definiu o próprio mesmo da América Latina em sua diferença em relação à Europa e ao Ocidente". E ainda: "Diversamente da Ásia e da África, a América tornou-se 'filha' e 'herdeira' da Europa durante o século 18".

${ }^{34}$ BORGES. América Latina, p. 18.

${ }^{35}$ BORGES. América Latina, p. 18.
} 
agora, nas duas outras declarações, um estatuto mais preciso: tratar-se-ia de um desterramento, de um exílio da cultura européia. Ora, um tal deslocamento, ao modo de um dépaysement, não ocorreria sem consequências para essa cultura que se desloca, que se veria "amplificada", sem dúvida, ao "atravessar o oceano", mas também, e num sentido importante, "deformada".

Com efeito, é toda a obra de Borges que poderia ser apreendida sob o signo dessa deformação fundamental do Ocidente - que se veria performada em suas leituras/reescritas do legado discursivo (literário, mitológico, teológico, filosófico, científico) da cultura ocidental -, sob o signo, portanto, de uma possível "identidade" (latino) americana, a ser compreendida não como uma entidade estática, como uma instância ontológica autocentrada, mas como identidade-em-ato.

Em nenhum outro texto Borges manifestou-se mais esclarecedoramente sobre esse ponto do que em "El escritor argentino y la tradición" (1953). "Qual é a tradição argentina?", perguntava-se, na ocasião, o autor. Ao que respondeu:

Creio que nossa tradição é toda a cultura ocidental, e creio também que temos direito a essa tradição, maior que o que podem ter os habitantes de qualquer outra nação ocidental. Lembro aqui de um ensaio de Thorstein Veblen, sociólogo norte-americano, sobre a primazia dos judeus na cultura ocidental. Ele se pergunta se essa primazia permite supor uma superioridade inata dos judeus, e responde que não: diz que eles sobressaem na cultura ocidental por que agem dentro dessa cultura e ao mesmo tempo não se sentem ligados a ela por uma devoção especial; "por isso-diz - sempre será mais fácil para um judeu do que para um ocidental não judeu inovar na cultura ocidental"; e podemos dizer o mesmo dos irlandeses na cultura da Inglaterra. (...) Creio que os argentinos, os sul-americanos em geral, estamos numa situação análoga, podemos lançar mão de todos os temas europeus, utilizá-los sem superstições, com uma 
irreverência que pode ter, e já tem, consequências afortunadas. ${ }^{36}$

É na relação com o acervo do discurso ocidental, num certo tipo de relação com esse acervo, que se entreveria, pois, uma "identidade" sul[latino]-americana, de acordo com Borges, uma identidade-em-ato. Nada seria mais representativo do tipo de relação a que se refere Borges do que o regime de leitura que ele próprio instituiu em seus escritos, em suas "ficções", do legado discursivo ocidental. Nas leituras em questão, é tudo aquilo que se encontrava conceitualizado, sistematizado, formalizado ao modo de "pensamentos", "teorias", "filosofias", em uma palavra: tudo aquilo que se encontrava arquivado, que se reverte, que se desarquiva em vista de um não-saber performado pelo próprio discurso borgiano. Nenhuma consequência terá sido, pois, mais "afortunada", nesse sentido, do que a própria obra de Borges.

Résumé: En partant d'une certaine aporie dans le coeur même du programme archéologique foucaldien, cet essai se tourne vers la mobilisation d'un texte de Borges par Foucault dans le préface de sa opus magnum, et montre que la relation hétérodoxe que l'écrivain argentin établit avec les «archives» de la tradition occidentale démobilise plutôt que favorise la prétention d'une archéologie du savoir.

Mots-clés: Foucault; archéologie; archive; Borges; "desarquivamento".

${ }^{36}$ BORGES. O escritor argentino e a tradição, p. 295. 


\section{Referências}

BORGES, J. L. América Latina. In: STORTINI, C. R. (Comp.) Dicionário de Borges: o Borges oral, o Borges das declarações e das polêmicas. Rio de Janeiro: Bertrand Brasil, 1990. p. 17-18.

BORGES, J. L. O escritor argentino e a tradição. In: Obras completas. v. 1. São Paulo: Globo, 1999a. p.288-296.

BORGES, J. L. O idioma analítico de John Wilkins. In: Obras completas. v. 2. São Paulo: Globo, 1999b. p.92-95.

DERRIDA, J. Mal de arquivo: uma impressão freudiana. Rio de Janeiro: Relume-Dumará, 2001.

FOUCAULT, M. A arqueologia do saber. 7. ed. Rio de Janeiro: Forense, 2005.

FOUCAULT, M. As palavras e as coisas: uma arqueologia das ciências humanas. 2. ed. São Paulo: Martins Fontes, 1981.

MIGNOLO, W. D. Histórias locais/projetos globais: colonialidade, saberes subalternos e pensamento liminar. Belo Horizonte: Editora UFMG, 2003.

Recebido para publicação em $1^{\circ}$ de maio de 2011. Aprovado em 24 de junho de 2011. 